New Magnetical Experiments. - M. Ader has performed some interesting experiments upon bodies which are slightly magnetic. He finds that elder pith is more sensitive than ordinary wood, paper, etc. With a Jamin magnet, sustaining a weight of $100 \mathrm{k} .(220 \cdot 46 \mathrm{lbs}$.$) ,$ and provided with two small polar armatures, separated by an interval of $2 \mathrm{~mm}$. ( $78 \mathrm{in}$.), he has been able to attract, at a distance of $3 \mathrm{~mm}$. (-118 in.), a pith ball of $5 \mathrm{~mm}$. (02 in.), suspended by a thread. He has been able even to raise it, and when once attached to the magnet considerable force is necessary in order to remove it.-Comptes Rendus.

\title{
Discovery of a New Elementary Body in the Lava of
} Vesuvius. - Prof. Seachi, the celebrated mineralogist and crystallugrapher, in studying the yellow incrustation which is found on certain portions of the Vesuvian lava ejected in 1631, and which he calls Vesbine, has discovered a body which differs in its character from all the known elements. He considers Vesbine as a vesbiate of alumina, and he regards vesbic acid as the oxacid of a new element, vesbium, which, according to the properties of its compounds, will probably stand between molybdenum and vanadium. Stas thinks that vesbium may be found in some of the common ores, where its presence has never been suspected because it has been confounded with some of the known acidifiable metals. - Bull. de l'Aced. Belg.

\section{Influence of Light, Copse and Mould on Forest Growth.} -M. Gurnaud has conducted a series of observations, during the past nineteen years, upon the solid contents of annual growth in a forest among the Jura mountains. He finds that: 1. Light, when it strikes the ground without having been sifted by foliage, stimulates the production of carbonic acid in the decompositions which are engendered by the hunus, together with a decomposition of the same gas by the chlorophyll. 2. The growth of wood diminishes when the underbrush inercepts, to any great extent, the access of light to the soil and diminishes its reflex action on the branches of the trees. 3. This interruption of reflex action is due mainly to the spread of the underbrush, for when it is kept trimmed the vertical shoots which are retained interpose no obstacle. 4. The mould, under too great a thickness; loses a part of its virtue, and, like barn-yard manure which is too deeply buried, remains inert for many years.-Comptes Rendus. C. 